\title{
새로운 $\mathrm{N}_{2} \mathrm{O}$ 계 세 자리 리간드의 합성과 전이금속 착물 안정도상수 \\ 김선덕* - 박영식 \\ 대구대학교 자연과학대학 물질과학부
}

(2003, 8. 27 접수)

\section{Synthesis of New $\mathrm{N}_{2} \mathrm{O}$ Tridentate Ligands and Their Stability Constants of Transition Metal Complexes}

\author{
Sun Deuk Kim* and Young Sik Park \\ Department of Material Science, Deagu Universit; Kyongsan 712-714, Korea \\ (Received August 27, 2003)
}

요 약. 피리던과 페놀을 포합하는 $\mathrm{N}_{2} \mathrm{O}$ 계 세 자리 리간드 2-[(2-pyridine-2- cthylamino)-methyl]-phenol(H-PEMP) 를 합성하였다. 또한 H-PEMP 페놀의 5-위치에 치환기로 브롬, 연슨 및 메톡시를 가지는 Br-PEMP, Cl-PEMP 및 $\mathrm{CH}_{3} \mathrm{O}$-PEMP를, 그리고 2-hydroxy-1-naphthalene기를 가진 Naph-PEMP을 합섬하였다. 합성된 각 리간드들을 수용액 에서 전위차 석정 결과 양성자 해러는 3 단계로 일어났으며, 계산된 각 리간드의 총괄 양성자 해리상수 $\log \beta)$ 값은 $\mathrm{CH}_{3} \mathrm{O}$-PEMP> Naph-PEMP> H-PEMP> Br-PEMP>Cl-PEMP의 순서로 Hammett식의 치환기 상숙 $\left(\sigma_{\mathrm{p}}\right)$ 값 크기 순서 와 일치하였다. 전이금속 이온들의 착물 안정도삼숫 $\left(\operatorname{logML}\right.$ 및 $\left.\log \mathrm{ML}_{2}\right)$ 값의 크기는 븜속이온에 따라 $\mathrm{Co}(\Pi)<\mathrm{Ni}(\Pi)<$ $\mathrm{Cu}(\mathrm{II})>\mathrm{Zn}$ (II)의 순서이었고, 치환기에 따른 각 리간드의 착물 안정도상수 값은 리간드의 촣괄 양성자 해리상수 값여 크기순서와 일치하였다.

주제어: 세 자리 리간드. 총괄 양성자 해리삼수, 착물 안정도상수

\begin{abstract}
Ligands, Br-PEMP, Cl-PEMP and $\mathrm{CH}_{3} \mathrm{O}$-PEMP having $\mathrm{Br}, \mathrm{Cl}$ and $\mathrm{CH}_{3} \mathrm{O}$ substituents at 5-position of the $\mathrm{N}_{2} \mathrm{O}$ tridentate ligand, 2-[(2-pyridine-2-ethylamio)-methyl]-phenol (H-PEMP) containing pyridine and phenol werc synthesized. Another ligand, Naph-PEMP having pyridine and 2-hydroxy-1-naphthalene was also synthesized. The ligands werc characterized using elemental analysis, UV-visible, IR, ' $\mathrm{H}$ NMR and ${ }^{13} \mathrm{C}$ NMR spectroscopy and mass analysis. The potentiometric titration study in aqueous solution revealed that the proton dissociation of the ligands occurred in three steps and the order of overall proton dissociation constants $(\log \beta)$ was $\mathrm{CH}_{3} \mathrm{O}$-PEMP $>$ Naph-PEMP $>\mathrm{H}-\mathrm{PEMP}$ $>$ Cl-PEMP $>$ Br-PEMP. The order of stability constants (logML and $\log \mathrm{ML} 2)$ of their transition metal complexes was $\mathrm{Co}(\mathrm{II})<\mathrm{Ni}(\mathrm{II})<\mathrm{Cu}(\mathrm{II})>\mathrm{Zn}(\mathrm{II})$. The order in their stability constants values of cach transition metal complex agreed well with that in overall proton dissociation constant value of the ligands.
\end{abstract}

Keywords: Tridentate Ligand, Overall Proton Dissociation Constant, Stability Constant

\footnotetext{
서 폰

풰놀성 히드록시기롤 가지는 산소- 질소계 세 자리 라간드는 이온결합 빛 배위결합을 이루어 적이금속 이

온든과 착물을 잘 생성한다. 이 때 착물의 특성운- 치환 기에 따라 크게 염향을 받음ㅁㄹㅗ 최근에는 착물 특성에 비치는 치환기 효과에 관한 연구들이 활랄하다. ${ }^{1-0}$ 폐놀을 프함하는 세 자리 $\mathrm{N}_{2} \mathrm{O}$ 계 시프염기 리간드에
} 
서 페놀성 히드록기의 양성자 해리상수 $\left(\log K_{n}^{\mathrm{H}}\right)$ 는 물이 나 더옥산-물 및 에탄을-물 혼합용매을 사용할 때 용매 의 극성변화에 따라 도는 페놀에 치환된 차환기의 종류 에 따라 톡성적으로 다양한 값을 나타넨다. 이때 페놀 성 히드록서기의 양성자 해려상수에서 치환기 효과는 치환기가 전자를 말어 주는 그룸과 전자를 당기는 그룹 에 따라 다르게 나타나고, 치환기의 위치가 오소, 메타 및 퐈라에 따라서도 다양한 값을 나타낸다. ${ }^{78}$ 또한 페 놀이 아닌 푀리딘에 치환기를 가진 러간드의 경우에도 물, 에탄올-물 혼합용매에서 양성자 해라상수는 치환기 의 종류 및 위치에 따라 다르게 나타넜다. ${ }^{9}$ 이와 같이 리간드의 양성자 해리상수 값은 치환기의 종류 및 위치 에 따라 서로 다르게 나타난다. 이때 리간드의 양성자 해리상수 값에 미치는 치환기 효과는 Hammatt식의 챠 환기 상수 $(\sigma)$ 를 이용하여 정량격으로 서로 비교 설명할 수 있다. ${ }^{10,11}$ 치환기 호과는 리간드의 양성자 해리상수 뿐만 아니라 전이금속 착물의 분광학적 및 전기화학적 성질에도 크게 영항을 끼친다. 따라서 Hammatt 식의 치환기 상수는 착물 특성의 비교 설명에도 이용되고 있 다. 그 예로 Coleman ${ }^{12}$ 은 페놀에 여러 치환기 $\left(\mathrm{Z}=\mathrm{H}, \mathrm{CH}_{3}\right.$, $\mathrm{Cl}, \mathrm{Br}, \mathrm{CH}_{3} \mathrm{O}, \mathrm{NAP}, \mathrm{NO}_{2}$ )를 가진 다섯 자러 시프염기 Z-SALDPT의 $\mathrm{Mn}(\mathrm{II})$ 착물 $\mathrm{Mn}(\mathrm{Z}-\mathrm{SALDPT}) \mathrm{NCS}$ 를 합 성하고, 이들 $\mathrm{Mn}(\mathrm{III})$ 착물의 환원전위 $(\mathrm{Ep})$ 값과 ${ }^{13} \mathrm{C}$ $\mathrm{NMR}$ 의 화학적 이동( $(\delta)$ 값을 측정하여 이들 측정값과 Hammatt식의 치환기 상수와의 상관관계를 비교 설명 하였다. 또한 Mn(Z-SALOPHEN) X(X=NCS-, $\mathrm{NO}_{2}, \mathrm{~N}_{3}^{-}$ ) 착물도 합성하여 각 치환기들이 전기 화학적 특성에 미치는 영향도 검토하였다. ${ }^{13}$ 이와에 치환기 효과에 관 한 연구는 주로 페눌의 파라 위치에 여려 치환기를 가 진 다섯 자리 산소-질소계 시프염기 전이금속 착물의 분괌학적 및 전기 화학적 특성에 관한 것이 보고되고 있다. ${ }^{14}$ 그러나 페놀에 치환된 여러 종류의 치환기들이 리간드의 양성자 해리상수 및 전이금속 착물 안정도상 수에 어떠한 영항을 주는 가에 대한 상관 관계에 관한 연구는 거의 없다.

본 연구에서는 퍼리던과 페놀을 포함하는 세 자리 $\mathrm{N}_{2} \mathrm{O}$ 계 리잔드 2-[(2-pyridine-2-ethylamino)-methyl]-phenol (H-PEMP)를 합성하고, H-PEMP의 페놀 5-위차에 치환 기로 브롬, 염소, 메톡시기 및 나프톨기롤 가지는 5bromo-2-[(2-pyridine-2-ethylamino)-methyl]-phenol(BrPEMP), 5-chloro-2-(2-pyridine-2-ethylamino)-methyl)phenol (Cl-PEMP), 5-methoxy-2-[(2-pyridine-2- ethylamino)
-methyl-phenol(CH330-PEMP) 및 1-[(2-pyritine-2-ethylamino)methyl]-naphthalen-2-ol(Naph-PEMP)을 합성하였다. 합 성된 리간드의 양성자 해리상수와 $\mathrm{Co}(\mathrm{II}), \mathrm{Ni}(\mathrm{II}), \mathrm{Cu}(\mathrm{II})$ 및 $\mathrm{Zn}(\mathrm{II})$ 이온의 착불 안정도상수를 전위차 적정법으로. 구하고, 각 치환기가 리간드의 양성자 해리상수 값과 착불 안정도상수 값에 미치는 영향을 검토하였다.

\section{심 험}

시약 및 기기. 리간드 합성에 사용돤 2-(2-aminoethyl)pyridine, 5-chlorosalicylialdehyde, 5-bromosalicylaldehyde, 2-hydroxy-1-naphthaldehyde는 Aldrich제 특급시약을 그 대로 사홍하였으며, 2-hydroxy-5-methoxy-benzaldehyde 와 각종 금속 업은 Fluka제 특급시약을 정제하지 않고 그대로 사영하였고, 무수 에탄올과 염산은 동성화학체 품을 사용하였다. 각종 유기용매는 Junsei제품을 정제 하지 않고 그대로 사용하였다. 전자 흡수 스펙트럼은 Shimadzu UV-160A 분광 광도계.로 측정하였으며, 적외 선 흡수 스펙트럼은 Shimadzu IR-470 분광광도계를 이 웅하였다. 그리고 'H NMR와 ${ }^{13} \mathrm{C}$ NMR 스퐥트럼은 Varian Mecury 300 NMR 분광기로 측정하였고, 원소 분석은 Carlo Erba사의 instrument 1106을 이용하였다. 초 순수중류수 제조는 Human Tech,사의 PURE UP을 사영하여 제조하였다. 그리고 질량스펙트럼은 JEOL사 의 High Resolution Mass 분광기 JMS 700을 사웅하였 고, 전위차 적정은 Metrohm 665 Dosimat 자동젹정기 와 Metrohm $605 \mathrm{pH}$ 메터를 사용하였다. 적정시의 온도 조절은 Metrohm제 항은셀과 Jejo Tech Co. RC-10V 함 온조를 사웅하여 $25 \pm 0.1^{\circ} \mathrm{C}$ 로 고정시키고 실헙을 행하 였다.

리간드 합성. 피리던과 페놀을 포함하는 $\mathrm{N}_{2} \mathrm{O}$ 계 세 자러 러간드들의 합성은 2-(2-aminoethyl) pyridine에 salicylaldehyde, 5-chlorosalicylaldehyde, 5-bromosalicylaldehyde, 2-hydroxy-5-methoxy-benzaldehyde 및 2hydroxy-1-raphthaldehyde를 각각 반응시켜 시프엽기를 얻었고, 아 시프염기를 $\mathrm{NaBH}_{4}$ 를 이용하여 이민기를 이 차 아민기로 환원시켰다. 합성된 각 화합물의 화학구조 는 Scheme 1과 2와 같다. ${ }^{15-17}$

\section{2-[(2-pyridine-2-ethylamino)-methyl]-phenol(H-PEMP)} $\mathbf{H C l}$ 의 합성. 무수 메탄올 $50 \mathrm{~mL}$ 에 2-(2-aminoethyl) pyridine $(0.02 \mathrm{M}, 2.5 \mathrm{~mL})$ 을 녹이고 salicylaldehyde $(0.02$ $\mathrm{M}, 2.3 \mathrm{~mL}$ )을 서서히 적은 양을 방울로 가하면서 $60^{\circ} \mathrm{C}$ 

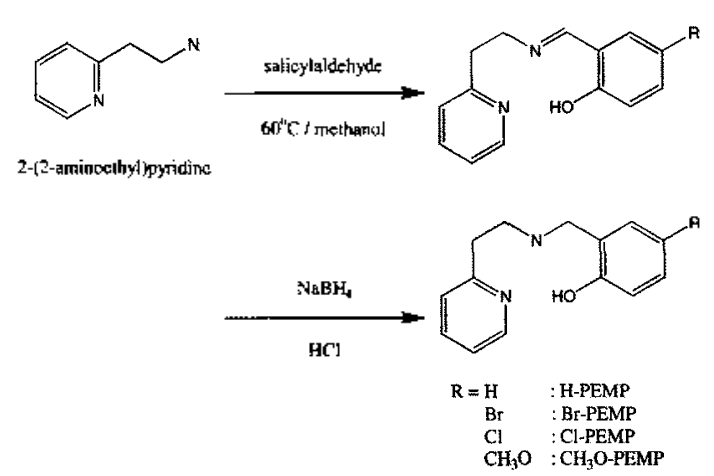

Sitheme 1 .

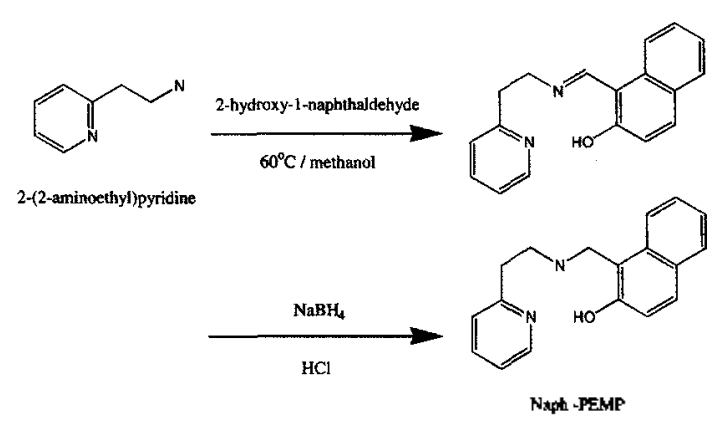

Scheme 2.

로 시간동안 교반시키면 노란색의 시프엽기 화합물이 챙성된다. 합성된 시프염기 화합물에 다시 메탄을 $50 \mathrm{~mL}$ 을 가하여 냉각시킨 다음 $\mathrm{NaBH}_{4}$ 를 조금씩 넣어 환원 시카년 서서허 노란색이 없어진다. 12 사간동안 반움시 킨 후 완전히 무색이 되었을 때 염산으로 $\mathrm{pH}$ 7 -8까지 충화시키면 횐색 침전물이 생긱다. 이를 여과하여 여핵 을 감압 증류하고 그 여액에 진한 $\mathrm{HC}$ 을 과량 넣은 다 음 이를 다시 감압 증류하여 PFMP.HCl 환색 침전눌을 얻는다. 이 휜새침전물을 $30 \%$ 메탄올 $70 \%$ 에탄울 혼 합붕매에서 재결정하여 진공 데시케이터 속에서 건조 하여 사용하였다.

Yield: $86 \%$. Anal. Calcd. for $\mathrm{C}_{14} \mathrm{H}_{16} \mathrm{~N}_{2} \mathrm{O} \cdot \mathrm{HCl}$ : C. 63.52; H, 6.47; N, 10.58. Found: C. 63.20; H, 6.79; N, 10.40\%). UV/vis(water), $\lambda_{\text {max }}, \mathrm{nm}\left(\varepsilon, \mathrm{M}^{-1} \mathrm{~cm}^{-1}\right): 261(3,300), 267$ (3,000). IR(KBr, cm '): $1668,3224(\delta \mathrm{N}-\mathrm{H}), 1460,1610$ $(\mathrm{vC}=\mathrm{C}), 3415(\mathrm{vO}-\mathrm{H})$. 'H NMR(D $\left.\mathrm{D}_{2} \mathrm{O}\right): \delta 3.20\left(\mathrm{CH}_{2} \mathrm{CH}_{2}\right.$ $2 \mathrm{H}), 3.20\left(\mathrm{CH}_{2} \mathrm{CH}_{2} 2 \mathrm{H}\right), 3.99\left(\mathrm{CH}_{2} 2 \mathrm{H}\right), 6.67$ (benzene $2 \mathrm{H}$ ), 7.05 (benzene $2 \mathrm{H}$ ), 7.64 (pyridine $2 \mathrm{H}$ ), 8.18 (pyridine $1 \mathrm{H}$ ). 8.37 (pyridine $1 \mathrm{H}$ ). ${ }^{13} \mathrm{C} \mathrm{NMR}\left(\mathrm{D}_{2} \mathrm{O}\right): \delta 31.14,46.15,48.64$, $116.91,118.32,122.19 .127 .36,128.85 .133 .27,143.23$,
$148.58,152.42,156.50$. Mass(GC-mass), th/e: $228\left(\mathrm{M}^{+}\right)$. 93(base).

5-Bromo-2-[(2-pyridine-2-ethylamino)-methyl]phenol (Br-PEMP).HC의 합섬. 무수 메탄올 $50 \mathrm{~mL}$ 에 2-(2-aminoethyl)pyridine $(0.02 \mathrm{M}, 2.5 \mathrm{~mL})$ 과 5-bromosalicylaldchyde $(0.02 \mathrm{M}, 4 \mathrm{~g})$ 을 가하여 PEMP와 같은- 방 법으로 $\mathrm{Br}-\mathrm{PEMP} \cdot \mathrm{HC}$ 을 합성하였다.

Yield: $82 \%$. Anal. Caled. for $\mathrm{C}_{14} \mathrm{H}_{15} \mathrm{BrN} \mathrm{N}_{2} \mathrm{O} \cdot \mathrm{HCl}$ : C, 51.28; H, 4.92; N 8.55. Found: $\mathrm{C}, 50.80 ; \mathrm{H}, 5.10 ; \mathrm{N}, 8.42$. UV/ vis(water), $\lambda_{\text {max }} \operatorname{nun}\left(\varepsilon, \mathrm{M}^{-1} \mathrm{~cm}^{-1}\right): 226(7,400), 261(3,900)$. $286(1,800), \operatorname{IR}\left(\mathrm{KBr}, \mathrm{cm}^{\prime}\right): 1630,3215(\delta \mathrm{N}-\mathrm{H}), 1470$. 1608(v C=C), 3445(v O-H), 580 650(vC-Br). 'H NMR $\left(\mathrm{D}_{2} \mathrm{O}\right): \delta 3.67\left(\mathrm{CH}_{2} \mathrm{CH}_{2} 2 \mathrm{H}\right), 3.39\left(\mathrm{CH}_{2} \mathrm{CH}_{2} 2 \mathrm{H}\right), 4.12\left(\mathrm{CH}_{2}\right.$ 2H), 6.73(benzene $1 \mathrm{H}$ ), 7.33(benzene 2H), 7.78(pyridine $2 \mathrm{H}), 8.39$ (pyridine $1 \mathrm{H}$ ), 8.49 (pyridine $1 \mathrm{H}$ ). ${ }^{13} \mathrm{C} \mathrm{NMR}\left(\mathrm{D}_{2} \mathrm{O}\right)$ : $\delta 31.14,46.32,48.00,112.85,118.81,120.51,127.20$, $128.75,135.47,135.61,143.44,148.26,152.56,155.92$. Mass(GC-mass), m/e: 306(M), 93(basc).

5-Chloro-2-[(2-pyridine-2-ethylamino)-methyl]-phenol (Cl-PEMP)-HCl의 합성. 무수 메탄올 $50 \mathrm{~mL}$ 에 2-(2amiwoethylypyridinc(0.02 M, $2.5 \mathrm{~mL})$ 과 5-chlorosalicylaldehyde $(0.02 \mathrm{M}, 3.2 \mathrm{~g})$ 을 가하여 PEMP 와 같-은 방법으로 ClPEMP·HCl를 합성하였다.

Yield: $89 \%$. Anal. Calcd. for $\mathrm{C}_{14} \mathrm{H}_{15} \mathrm{ClN}_{2} \mathrm{O} \cdot \mathrm{HCl}: \mathrm{C}, 59.37$; H. 5.69; N, 9.89. Found: C, 58.00; H, 5.78; N. 9.50. UV/ vis(water), $\lambda_{\text {max }}, \mathrm{nm}\left(\varepsilon, \mathrm{M}^{-1} \mathrm{~cm}^{-1}\right) ; 226(6,400), 262(3,600)$, $286(1,800)$. IR(KBr, cm$\left.{ }^{-1}\right): 1625,3225(\delta \mathrm{N}-\mathrm{H}), 1465$, $1605(\mathrm{~V} \mathrm{C}=\mathrm{C}), 3475(\mathrm{~V}$ O-H). 595 780(v C-Cl). 'H $\mathrm{NMR}\left(\mathrm{D}_{2} \mathrm{O}\right): \delta 3.38\left(\mathrm{CH}_{2} \mathrm{CH}_{2} 2 \mathrm{H}\right), 3.38\left(\mathrm{CH}_{2} \mathrm{CH}_{2} 1 \mathrm{H}\right)$, $4.13\left(\mathrm{CH}_{2} 2 \mathrm{H}\right), 6.79$ (benzene $\left.\mathrm{IH}\right), 7.19$ (benzene $2 \mathrm{H}$ ), 7.79 (pyridine $2 \mathrm{H}$ ), 8.39 (pyridine $1 \mathrm{H}$ ), 8.49 (pyridine $\mathrm{lH}$ ). ${ }^{13} \mathrm{C}$ NMR( $\left.\mathrm{D}_{2} \mathrm{O}\right): \delta$ 31.14. 46.32, 48.02, 118.33, 120.07 , 125.74, 127.21, 128.75, 132.55, 132.63, 143.48, 148.26. 152.58, 155.44. Mass(GC-mass), mve: 262(M+), 93(base).

5-Methoxy-2-[(2-pyridine-2-ethylamino)-methyl]phenol $\left(\mathrm{CH}_{3} \mathrm{O}\right.$-PEMP $) \cdot \mathrm{HCl}$ 의 합섬. 무수 메탄올 $50 \mathrm{~mL}$ 에 2-(2-aminothyl)pyridine $(0.02 \mathrm{M}, 2.5 \mathrm{~mL})$ 과 2-hydroxy5-methoxy-benzaldehyde $(0.02 \mathrm{M}, 2.6 \mathrm{~mL})$ 을 가하여 PEMP와 같은 방법으로 $\mathrm{CH}_{3} \mathrm{O}-\mathrm{PEMP} \cdot \mathrm{HCl}$ 를 합성하였다.

Yield: $85 \%$. Anal, Calcd. for $\mathrm{C}_{15} \mathrm{H}_{18} \mathrm{~N}_{2} \mathrm{O}_{2} \cdot \mathrm{HCl}$ : C, 61.12; $\mathrm{H}, 6.50 ; \mathrm{N}, 9.50$. Found: $\mathrm{C}, 60.05 ; \mathrm{H}, 6.78: \mathrm{N}, 9.30 . \mathrm{LV} /$ vis(water), $\lambda_{\text {man, }}, \operatorname{mn}\left(\varepsilon, \mathrm{M}^{-1} \mathrm{~cm}^{-1}\right): 226(4,500), 261(3,100)$ 
294(2,300). IR(KBr, cm $\left.{ }^{-1}\right): 1630,3235(\delta \mathrm{N}-\mathrm{H}), 1470$, $1607(v \mathrm{C}=\mathrm{C}), 3500(\vee \mathrm{O}-\mathrm{H})$. ${ }^{l} \mathrm{HNMR}\left(\mathrm{D}_{2} \mathrm{O}\right): \delta 3.40\left(\mathrm{CH}_{2} \mathrm{CH}_{2}\right.$ $2 \mathrm{H}), 3.40\left(\mathrm{CH}_{2} \mathrm{CH}_{2} 2 \mathrm{H}\right), 3.61\left(\mathrm{CH}_{3} \mathrm{O} 3 \mathrm{H}\right), 4.19\left(\mathrm{CH}_{2} 2 \mathrm{H}\right)$, 6.91 (benzene $3 \mathrm{H}$ ), 7.91 (pyridine $2 \mathrm{H}$ ), 8.39 (pyridine $1 \mathrm{H}$ ), 8.59 (pyridine $1 \mathrm{H}) .{ }^{13} \mathrm{C}$ NMR( $\left.\mathrm{D}_{2} \mathrm{O}\right): \delta 31.15,46.28,48.39$, $57.44,118.07,118.35,119.11,123.26,127.18,128.64,143.48$, $148.01,150.54,152.64,153.60$. Mass(GC-mass), m/e: $258\left(\mathrm{M}^{+}\right), 93$ (base).

1-[(2-pyridine-2-ethylamino)-methyl]-naphthalen-2-ol (Naph-PEMP).HC의 합섬. 무수 메탄을 $50 \mathrm{~mL}$ 에 2 (2-aminoethyl)pyridine $(0.02 \mathrm{M}, 2.5 \mathrm{~mL}$ )과 2-hydroxy-1naphthaldehyde $(0.02 \mathrm{M}, 3.5 \mathrm{~mL})$ 을 가하여 PEMP와 같 은 방멉으로 합성하여 Naph-PEMP.HCl를 얼었다.

Yiejd: 89\%. Anal. Calcd. for $\mathrm{C}_{18} \mathrm{H}_{18} \mathrm{~N}_{2} \mathrm{O}-\mathrm{HCl}$. C, 68.68; H, 6.08; N, 8.90. Found: C, 68.80; H, 6.10; N, 8.50. UV/ vis(water), $\lambda_{\text {max }} \mathrm{nm}\left(\epsilon, \mathrm{M}^{-1} \mathrm{~cm}^{-1}\right): 261(5,600), 332(1,900)$. $\operatorname{IR}\left(\mathrm{KBr}, \mathrm{cm}^{-1}\right): 1650,3215(\delta \mathrm{N}-\mathrm{H}), 1462,1612(\mathrm{~V} \mathrm{C}=\mathrm{C})$, $3510(v \mathrm{O}-\mathrm{H})$. ${ }^{1} \mathrm{H}$ NMR(D $\left(\mathrm{D}_{2} \mathrm{O}\right) ; 83.29\left(\mathrm{CH}_{2} \mathrm{CH}_{2} 2 \mathrm{H}\right), 3.32$ $\left(\mathrm{CH}_{2} \mathrm{CH}_{2} 2 \mathrm{H}\right), 4.59\left(\mathrm{CH}_{2} 2 \mathrm{H}\right), 7.0 \mathrm{l}$ (naphthalene $\left.1 \mathrm{H}\right), 7.25$ (naphthalene $1 \mathrm{H}$ ), 7.42(pyridine $2 \mathrm{H}$ ), 7.72(naphthalene $4 \mathrm{H}$ ), 8.27(pyridine $\mathrm{iH}$ ), 8.45(pyridine $1 \mathrm{H}$ ). ${ }^{13} \mathrm{C} \mathrm{NMR}\left(\mathrm{D}_{2} \mathrm{O}\right.$ ): $\delta 31.18,43.31,46.42,109.52,118.70,122.76,125.34$, $127.19,128.65,129.40,129.88,130.53,133.77,133.99$, $143.34,148.07,152.64,155.78$. Mass(GC-mass), m/e: 278( $\mathrm{M}^{+}$), 93(base).

전위차 법에 의한 리간드의 양성자 해리삼수 결점. 합성된 각 리간도의 양성자 해리상수 값을 얻기 위한 실험은 H-PEMP.HCI, Br-PEMP.HCl, Cl-PEMP.HCl, $\mathrm{CH}_{3} \mathrm{O}-\mathrm{PEMP} \cdot \mathrm{HCl}$ 및 Naph-PEMP.HCl 각 리간드를 수 뵹액에 녹여 $2.5 \times 10^{-3} \mathrm{M}$ 이 되도록 만들어 $0.1 \mathrm{M} \mathrm{KOH}$ 수용액으로 전위차 법으로 적정하여 적정 중 변화되는 $\mathrm{pH}$ 값을 축점하였다. 이매 적정핵의 이온세기 $(\mu)$ 는 $0.1 \mathrm{M}$ $\mathrm{KNO}_{3}$ 로 0.1 이 되게 하였다. 적정용액의 내부에 존재하 는 $\mathrm{O}_{2}$ 와 $\mathrm{CO}_{2}$ 의 영향을 줄이기 위해 질소기류를 통과시 켜 격정하였고 물의 이온곱 $(\mathrm{Ks})$ 은 $10^{-1378}$ 값을 사용하 여 계산하였다. 측정된 $\mathrm{pH}$ 값으로부터 각 리간드의 양 성자 해러상수 값은 Fortran 77로 만돌어진 PKAS 프 로그램을 사옹하여 계산하였다. ${ }^{18}$

전위차 법에 의한 착물 안정도상수 겸점. 합성된 각 러간드와 $\mathrm{Co}(\mathrm{II}), \mathrm{Ni}(\mathrm{II}), \mathrm{Cu}(\mathrm{II})$ 및 $\mathrm{Zn}(\mathrm{I})$ 열 $2.5 \times 10^{-3} \mathrm{M}$ 수욤액을 $0.1 \mathrm{M} \mathrm{KOH}$ 수움역으로 전위차법으로 적점 하여 적정 중 변화되는 $\mathrm{pH}$ 값을 측정하였다. 이때 착물
외 안정도상수를 구할 때 사용되는 기본 값으로 리간드 농도(mmole), $\mathrm{KOH}$ 의 농도(mole)와 부퍼( $\mathrm{mL})$, 붕핵의 초기 부푀 $(\mathrm{mL})$, 려간드의 양섬자 해리단계 수, 용매의 $p K_{w}$ 값, $\mathrm{CO}_{2}$ 의 퍼센트 및 적가된 $\mathrm{KOH}$ 의 부피 $(\mathrm{mL})$ 에 따른 $\mathrm{pH}$ 의 변화 값을 BEST 프로그램에 입력하여 $\sigma_{f t}$ 값이 0.03 이하의 값을 얼어낸다. 그리고 컴퓨터 연산 자는 적정곡선으로부터 언은 평형값을 입력하여 $K_{M L}$ 값 과 값을 $1.0 \times 10^{-3}$ 씩 반복하여 증가시키면서 $\sigma_{f i t}$ 값을 보정하여 BEST 프로그램에 의헤 계산된 착물 안정도 상수 값을 얻었다. ${ }^{17}$

\section{결과 및 고찹}

리간드의 합섬. 염산 염 형태로 합성된 H-PEMP.HCl, $\mathrm{Br}$-PEMP-HCl, Cl-PEMP.HCl, $\mathrm{CH}_{3} \mathrm{O}$-PEMP.HCl 및 Naph-PEMP.HC의 C, H, N 원소분셕 결과는 실헙치와 계,산치가 잘 일치하였고, 자외선 홉수스펙트럼 결과는 각 리간드의 극대흡수 봉우리 $\left(\lambda_{\text {max }}\right)$ 가 226 332 nm 범 위에서 나타났다. 이는 아민기로 인한 $n \rightarrow \pi^{*}$ 전자전 이와 뻰젠 및 푀리던의 이중결합에 의한 $\pi \rightarrow \pi^{*}$ 의 전 자전이에 의한 흡수 때문이다. ${ }^{15,16}$ 이들 리간드의 적외 선 홉수스펙트럼 결과룰 보면 $1640 \mathrm{~cm}^{-1}$ 근처에서 나 타나는 시표염기의 이민기의 봉우리는 환전히 이차 아 민기로 환원되어 나타나지 않았다. N-H 신축진동은 $3415 \sim 3520 \mathrm{~cm}^{-1}$ 근처에서 폭넓게 나타넜고, N-H 굽힘 진동은 $1625-1668 \mathrm{~cm}^{-1}$ 에서 방항족의 $\mathrm{C}=\mathrm{C}$ 이줌결합 의 신축진동은 $1460 ~ 1470$ 과 $1605 \sim 1612 \mathrm{~cm}^{-1}$ 범위의 두 곳에서, $\mathrm{Br}$-PEMP과 $\mathrm{Cl}-\mathrm{PEMP}$ 의 $\mathrm{C}-\mathrm{Br}$ 과 $\mathrm{C}-\mathrm{Cl}$ 의 신 축진동은 $580-780 \mathrm{~cm}^{-1}$ 범위 내에서 나타났다.

'H NMR 스펙트럼 결과는 H-PEMP의 탄소사슬의 수 소는 $3.20,3.22$ 및 $3.99 \mathrm{ppm}$ 세 곳에서, 벤젠의 수소는 6.67 과 $7.05 \mathrm{ppm}$ 두 곳에서, 푀리던외 수소는 7.64, 8.18 및 $8.37 \mathrm{ppm}$ 세 곳에서 나타났다. Br-PEMP 및 Cl-PEMP 는 H-PEMP와 같이 탄소사슬의 수소가 3.38 4.13 ppm 범위의 세 곳에서 봉우리가 나타났고, 벤젠고리의 수소 는 치환기를 가지므로 $6.73 \sim 7.33 \mathrm{ppm}$ 법위에서 PEMP 와 다른 비 값의 봉우리가 나타썼고, 피리댄의 수소는 H-PEMP와 같이 세 곳에서 나타넜다. $\mathrm{CH}_{3} \mathrm{O}$-PEMP는 메톡시기의 수소가 $3.61 \mathrm{ppm}$ 에서 나타넜고, Br-PEMP 및 Cl-PEMP 경우와 유사하게 나타났다. Naph-PEMP는 탄소사슬과 피린던의 수소가 H-PEMP의 경우와 거의 같았고, 나푸톨의 수소는 7.01, 7.25, $7.72 \mathrm{ppm}$ 세 곳에 
서, 폐라던의 수소는 H-PEMP와 같이 세 곳에서 각각 나타났다. ${ }^{13} \mathrm{C}$ NMR의 결과를 보면 PEMP, Br-PEMP 및 Cl-PEMP의 이차 아민기 근처의 탄소는 $\delta$ 가 31.14 $46.64 \mathrm{ppm}$ 법휘에서 세 개의 봉우려가 나타났고, 피리 던을 포핚한 벤센고리의 탄소는 112.19 156.5 ppm 범 위에서 나타났다. 그러나 H-PEMP는 피러던과 벤젠고 리의 탄소 봉우리가 $122.19 \mathrm{ppm}$ 에서 겹쳐 나타나 열 개의 봉우러가 나타넜고, Br-PEMP 및 Cl-PEMP는 겹 친 봉우리가 없어 열한 개의 봉우리가 나타났다. $\mathrm{CH}_{5} \mathrm{O}$ $\mathrm{PEMP}$ 는 Br-PEMP 및 CJ-PEMP의 경우와 거의 같핬으 나 매톡시가의 탄소봉우러가 $57.44 \mathrm{ppm}$ 에서 나타났다. Naph-PEMP의 경-우 아빈기 근처의 탄소는 H-PEMP 동 과 거의 같았고, 퍼리딘을 포함한 나쁘톨기의 탄소는 109.52 155.7 ppm에서 열 나섯 개의 봉우리가 가각 나 타났다.

진량스뻭트럼의 견자를 보면 H-PEMP의 경-우 분자 량에 해당하는 분자이옥 $\left(\mathrm{M}^{+}\right)$봉우리가 질량 대 전하 비 값(m/e)이 228에서 나타났고, 93에서 나타나는 기준봉 -우리는 푀리던에 메털기가 한 개 더 포핚된 질량 값 $\left(\mathrm{C}_{6} \mathrm{H}_{7} \mathrm{~N}\right)$ 이다, Br-PEMP 경우 분자량에 해당하는 분자 이온 $\left(\mathrm{M}^{+}\right)$봉우리가 306 에서 나타났고, Cl-PEMP는

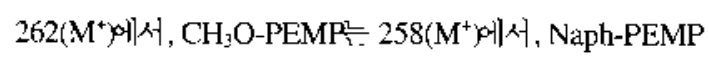
는 $278\left(\mathrm{M}^{+}\right)$에서 나타났다. 기준농웅러는 H-PEMP와 같 이 모두 93에서 나타났다. 또한 보는 리간츠 합성에서 출발물질인 2-(2-aminocthyl)pyridinc 진량에 해당하는 121 의 봉우러가 공통으로 나타넜으며, 각 치확기 $(\mathrm{Br}-, \mathrm{Cl}-$ $\mathrm{CH}_{3} \mathrm{O}$-)에 해당하는 번절봉우리도 확인할 수 있었다. 위 에서 고찰한 자외선 홉수분광법, 적와선 흡수분광법, ${ }^{1} \mathrm{H}$ $\mathrm{NMR}$ 및 ${ }^{13} \mathrm{C} \mathrm{NMR}$ 분광법, 질량분석법 및 $\mathrm{C}, \mathrm{H}, \mathrm{N}$ 원소 분석법의 결과를 동하여 피리던과 페놀을 포함하는 세 자리 $\mathrm{N}, \mathrm{O}$ 계 러간드 H-PEMP.HCl, Br-PEMP.HCl, Cl$\mathrm{PEMP} \cdot \mathrm{HCl}, \mathrm{CH}_{3} \mathrm{O}-\mathrm{PEMP} \cdot \mathrm{HCl}$ 및 Naph-PEMP.HC의 합 성을 확인할 수 있었다.

전위차법에 의한 리간드의 양성자 해리상수 결정. 합 성한 각 러간드률 $0.1 \mathrm{M} \mathrm{KOH}$ 염기 표준용-액으로 전위 차 적정하여 적정 중 변화되는 수소이온농도로부터 계 산된 각 리간느들의 양성자 해리상수 $\left(\log \mathrm{K}_{\Perp}^{\mathrm{H}}\right)$ 값은 Table 1에 나타내었다. Table 1의 결과에서 합성된 각 리간드 는 모두 3 단계로 양성사 해리가 일어남을 알 수 있다. 이때 페놀성 히드록기 양성자의 해리상수 $\left(\operatorname{logK}_{1}^{H}\right)$ 은 9.27 10.51 범위에서, 이차 아진기의 양성자 해리상수 $\left(\log \mathrm{K}_{2}^{15}\right)$ 은 6.10 -9.55 범위에서, 피러넌의 양성자 해러
Table 1. Proton dissociation constants for $\mathrm{CH}_{3} \mathrm{O}-\mathrm{PEMP}$, NaphPEMP H-PEMP, Cl-MPEP, and Br-MPEP in water alt $25^{\circ} \mathrm{C}$ and $\mu=0.1\left(\mathrm{KNO}_{3}\right)$

\begin{tabular}{lrrrr}
\hline \hline Ligand & $\log K_{1}{ }^{\mathrm{H}}$ & $\log K_{2}{ }^{\mathrm{H}}$ & $\log K_{3}{ }^{\mathrm{H}}$ & $\log \beta$ \\
\hline Br-PEMP & 9.27 & 6.10 & 1.34 & 16.71 \\
Cl-PEMP & 9.39 & 6.72 & 1.56 & 17.67 \\
H-PEMP & 9.62 & 7.57 & 1.83 & 19.02 \\
Naph-PEMP & 9.87 & 7.63 & 2.56 & 20.06 \\
$\mathrm{CH}_{3} \mathrm{O}-\mathrm{PEMP}$ & $10.5 \mathrm{l}$ & 9.55 & 2.78 & 22.84 \\
\hline
\end{tabular}

상수 $\left(\operatorname{logK}_{3}{ }^{\mathrm{H}}\right)$ 은 1.34 2.78 범위에서 가ㄱㅏㅏ 나타넜다. 각 리간츠의 총괄 양성자 해리상수 $(\log \beta)$ 값은 $\mathrm{CH}_{3} \mathrm{O}$ PEMP $>$ Naph-PEMP $>$ H-PEMP $>$ Cl-MPEP $>$ Br-MPEP 의 순서로 나타났다. 이 견과에서 총괄 양성자 해리상 수 값은 치환기가 전자를 밀이주는 그룹일수록 큰 값을 나타나는 경향을 보여 준다. 이와 같은 경향은 방향족 화합물의 치환기 호과를 정량직으로 나타내는 Hammett 식의 치환기상수 $(\sigma)$ 값은 이용하여 설명한다. Hammell 식에서 치환기는 전자를 밀어주는 - 그룹 $\left(\mathrm{CH}_{3} \mathrm{O}-\mathrm{H}-, \mathrm{CH}_{3}-\right)$ 과 선자를 당기는 그룹( $\left.\mathrm{NO}_{2}-, \mathrm{Br}-, \mathrm{Cl}-\right)^{\circ}$ 으로 나눌 수 있 다. 이 때 여러 치환기가 파라 위치에 치환되어 있을 때 치환기상수 $\left(\sigma_{1}\right)$ 값의 크기는 $\mathrm{CH}_{3} \mathrm{O}-<\mathrm{H}-<\mathrm{Cl}-<-\mathrm{Br}$ 의 순서로 증가한다. 1012 득히 살리실알뎨히드의 경우 결합 된 치환기가 전자를 민어주는 고룹을 가진 리간드의 염 기호는 높아지고, 전자를 당기는 그룹의 리간드의 혐기 도는 낮하지는 겅항을 가진다. ${ }^{7-9}$ 따라서 페놀성 히츠록 시기의 양성자 해리상숙 $\left(\log \mathrm{K}_{]}{ }^{\mathrm{H}}\right)$ 값을 보면 $\mathrm{Br}$-PEMP 의 경-우는 9.27 로 가장 작은 값을 나타내고. $\mathrm{CH}_{3} \mathrm{O}$ PEMP은 10.51로 가장 큰 값을 나타나는 것으로 생가횐다.

Table 1에서와 같이 합성된 리간드의 패놀성 히드록. 시기 양성자 해러상수 $\left(\log \mathrm{K}_{I}{ }^{\prime \prime}\right)$ 값은 총괄 해러삼수 $(\log \beta)$ 값과 같이 $\mathrm{Br}-\mathrm{PEMP}<\mathrm{Cl}-\mathrm{PEMP}<\mathrm{H}-\mathrm{PFMP}<\mathrm{Naph}-\mathrm{PEMP}$ $<\mathrm{CH}_{3} \mathrm{O}$-PEMP의 순으로 충가하는 것을 알 수 있다.

전위차 적정 중 염기가 적가된에 따라 적정 중 생성 되는 양성자 해리 분포율은 Fig. 1과 같다. Fig. 1의 결 과를 보면 적정 중 생정되는 $\mathrm{H}_{3} \mathrm{~L}, \mathrm{H}_{2} \mathrm{~L}, \mathrm{HL}$ 및 L 화학 종 봉우리의 전쳬적인 분포는 합성된 각 러간드든의 페 놓의 히드록시기 양성자 해리상수 값 $\left(\log \mathrm{K}_{1}{ }^{11}\right)$ 과 홍괄 양성자 해리상수 값 $(\log \beta)$ 의 크기 순서와 같이 오른쪽 으로 이동하는 경항을 보였다. 또한 Fig, 의 결과에서 와 같이 치황기상수 $\left(\sigma_{\mathrm{p}}\right)$ 값이 가창 큰 $\mathrm{CH}_{3} \mathrm{O}-\mathrm{PEMP}$ 의 해리 분포곡선이 가장 오른쪼으로 이동하는 경향과노. 일치하였다. 따라서 합성된 러간드의 양성자 해러 분포 

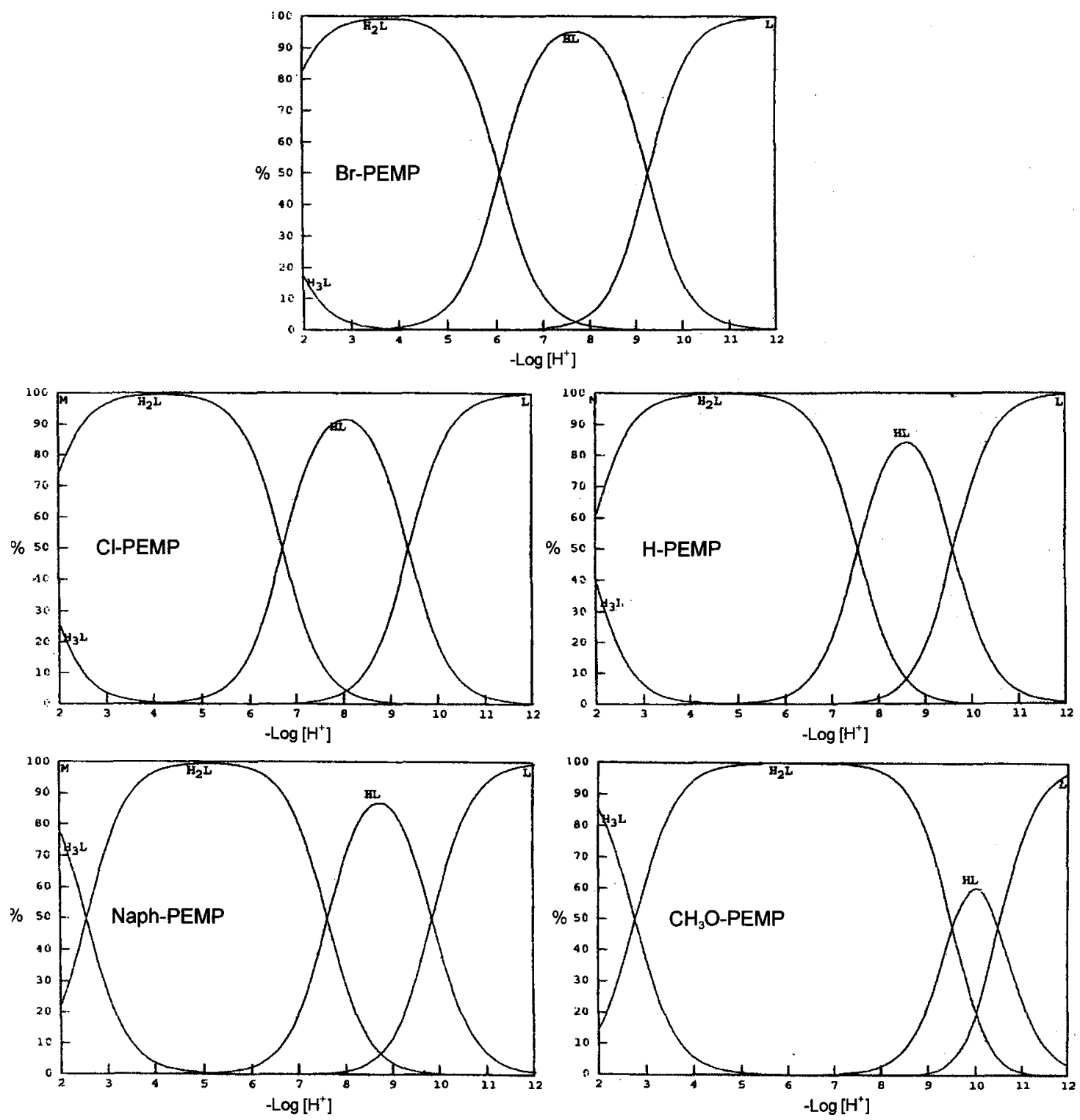

Fig. 1. Relative concentrations of Br-PEMP, Cl-PEMP, H-PEMP, Naph-PEMP, and $\mathrm{CH}_{3} \mathrm{O}-\mathrm{PEMP}$ species formed as a function of $-\log \left[\mathbf{H}^{+}\right]$in water.

율 곡선은 각 치환기에 외한 리간드의 염기도 영항을 설명하여 준다.

전위차법에 의한 착글 안정도상수 결정. 합성된 세 자러 리간드의 H-PEMP의 양청자 해러 전위차 적정곡 선과 $\mathrm{Co}(I I), \mathrm{Ni}(\mathrm{II}), \mathrm{Cu}(\mathrm{II})$ 및 $\mathrm{Zn}(\mathrm{II})$ 이온의 착물 안정 도상수 결정을 위한 전위차 적정곡선을 Fig. 2에 나타 내었타. Fig. 2 의 전위차 적정곡선의 결과와 같이 H-PEMP 의 양성자 해리는 중화도 값이 $\mathrm{a}=3$ 이전에 완전히 해
리됨을 알 수 있고, 금속이온과 H-PEMP의 전위차 적 정곡선에서 $\mathrm{Cu}$ (H)의 경우 $\mathrm{ML}$ 착물은 중화도 값이 $\mathrm{a}=3$ 정도 범위일 때 착물이 생성됨을 알 수 있고, $\mathrm{Ni}(\mathrm{II})$, $\mathrm{Co}(\square)$ 딫 $\mathrm{Zn}$ (파의 경우 $\mathrm{ML}$ 착물은 $\mathrm{a}=1.5 \sim 2.0$ 일 때, $\mathrm{ML}_{2}$ 의 착물은 $\mathrm{a}=3.5-4.0$ 정도에서 생성됨을 알 수 있 다. 여기서 중화도 a값은 염기를 져가할 때 양성자가 중 화되는 열기의 담랑을 나타낸다. 이때 적정을 통해 염 기가 적가뒴에 따라 웅액의 수소이온농도가 감소하여 


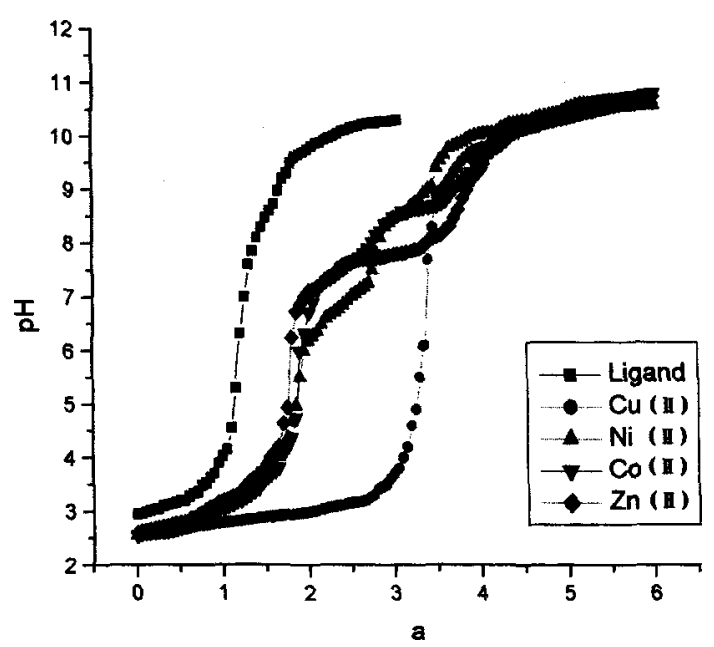

Fig. 2. Potentiometric equilibrium curves of H-PEMP complexes of $\mathrm{Cu}(\mathrm{II}) . \mathrm{Ni}(\mathrm{II}), \mathrm{Co}(\mathrm{II})$, and $\mathrm{Zn}(\mathrm{II})$ in water at $25^{\circ} \mathrm{C}$ and $\mu=0.1\left(\mathrm{KNO}_{3}\right) ; \mathrm{KOH}=0.1 \mathrm{M} ; \mathrm{T}_{\mathrm{L}}=\mathrm{T}_{\mathrm{M}}=1.0 \times 10^{-3} \mathrm{M}$. $a$ is the number of equivalents of $\mathrm{KOH}$ added.

양정자와 경쟁반웅이 감소되여 착물 생성이 왕이하케 된다.

Fig. 2와 같이 전위차 적정 중 변화되는 $\mathrm{pH}$ 값를 BEST 프로그램을 이용하여 계산한 착물 안정도상수 $(\log M L$ 및 $\log \mathrm{ML}_{2}$ ) 값은 Table 2 에 나타갰다.

Table 2에서 보듯이 전이금속에 따라 착불의 안정도 상수 값은 $\mathrm{Co}(\mathrm{II})<\mathrm{Ni}(\mathrm{I})<\mathrm{Cu}(\mathrm{II})>\mathrm{Zn}$ (II)의 순서로 나 타났다. 일반적으로 안정도삼수의 크기는 금속이혼의 전하밀도가 쿨수록, 그리고 금속이옹의 크기가 작을수 록 착물의 한정도는 커지므로 결과에서 착물 안정도상 수값은 $\mathrm{Co}(\mathrm{II})<\mathrm{Ni}(\mathrm{ll})<\mathrm{Cu}(\mathrm{II})>\mathrm{Zn}(\mathrm{II}$ 의 순서로. IrvingWilliams 순서와 일치하고 있다. 그리고 착물 안정도상 수는 양성자 해리상수 값에 큰 영향을 받는다. 따라서 총괄 양성자 해리상수 값이 제일 큰 $\mathrm{CH}_{3} \mathrm{O}$-PEMP의 경 우 전이금녹이온들과 착물의 안정도상수는 가장 큰 값 을 나타낸다. 이는 $\mathrm{CH}_{3} \mathrm{O}$-PEMP의 메톡시기가 전자를 밀어주게 되어 페놀의 히드록시거 산소에 전자밀도가
증가하여 염기도가 증가하므로 전이금속이온들자 착물 을 잘 생성할 수 있기 때문오로 생각된다. 이화 같이 치 환기는 착물 안점도상숭에 영항을 준다. 그리고 치환기 가 서로 다른 각 리간쯔의 전이귺속 착물 한정도상수 값은 Hammett식의 치환기 상수 $\left(\sigma_{\mathrm{p}}\right)$ 크기 순서인 $\mathrm{CH}_{3} \mathrm{O}$ PEMP $>$ Naph-PEMP $>$ H-PEMP $>$ Cl-PEMP $>$ BI$\mathrm{PEMP}$ 로 증가함을 알 수 있다. ${ }^{12.13}$ 이와 같이 리간드에 치환기들은 안정도상수 값 이외에 착눌의 다른 톡섬에 도 영햠을 준다, 그 예로 $\mathrm{Mn}$ (III)와 산소-질소계 다섯 자러 시프염기 SALDPT의 착물 $\mathrm{Mn}(\mathrm{ZSALDPT}) \mathrm{NCS}$ $\left(\mathrm{Z}=5-\mathrm{H}, 5-\mathrm{NO}_{2}, 5-\mathrm{Br}, 5-\mathrm{OCH}_{3}\right.$. Naph 등)의 경우을 보 면 착물 환원전위(Ep)값은 치환기에 따라 $-\mathrm{NO}_{2}<-\mathrm{Br}<$ $-\mathrm{H}<-\mathrm{OCH}_{3}<-\mathrm{Naph}$ 순서로 증가하였고, 페놀 $\mathrm{C}-\mathrm{O}$ 기 탄소의 ${ }^{13} \mathrm{CNMR}$ 의 화학적 이동 ( $(\delta)$ 값은 $-\mathrm{NO}_{2}<-\mathrm{OCH}_{3}$ $<-\mathrm{Br}<-\mathrm{H}<-\mathrm{Naph}$ 의 순서로 큰 값을 나타내었다. ${ }^{12}$ 이 와 같이 치환가는 종류 및 위치에 따라 착물 톡성에 크 게 영항을 주는 것을 알 수 있다.

Fig. 3은 $\mathrm{Co}(\mathrm{II}), \mathrm{Ni}(\mathrm{II}), \mathrm{Cu}(\mathrm{II})$ 및 $\mathrm{Zn}(\mathrm{II})$ 금속이온과 HPEMP 용액을 염기로 전위차 적정 중 생성되는 각종 화 학종의 분포곡선이다. Fig. 3 의 결과를 보면 $\mathrm{pH}$ 6 8범 위 영역에서 금속이온과 H-PEMP의 혼합물은 적정이 진행됨에 따라 러간드의 양성자는 거의 해리되어 $\mathrm{H}_{2}$ 와 $\mathrm{HL}$ 화학종은 사라지고 $\mathrm{ML}$ 착불이 생성이 완료되고, $\mathrm{ML}_{2}$ 착물 생성이 시작되는 $\mathrm{pH}$ 범위임을 알 수 있다. 이 때 적정이 더 진행되어 협기가 더 석가되면 $\mathrm{ML}_{2}$ 착 물이 생성된다. 이때 ML형 화학종의 분포율이 낮고 $\mathrm{ML}_{2}$ 형의 화학종의 분포율이 높은 것은 Table 2의 착물 한정도상수 값 $\left(\log M L\right.$ 및 $\left.\log \mathrm{ML}_{2}\right)$ 의 결과와 같았다. 이 결과는 한 예로 H-PEMP와 거의 같은 화학구조를 가 진 세 자러 $\mathrm{N}_{2} \mathrm{O}$ 곅 시프염기 SALZ-AMP화 SALZ-AEMP $\left(\mathrm{Z}=5-\mathrm{H}, 5-\mathrm{NO}_{2}, 5-\mathrm{Cl}, 5-\mathrm{CH}_{3} \mathrm{O}\right.$, Naph)의 경우을 보면 1:1의 $\mathrm{ML}$ 형 $\mathrm{Cu}(\mathrm{II})$ 착물은 $\mathrm{H}_{2} \mathrm{O}, \mathrm{DMSO}$ 및 $\mathrm{CHCl}_{4}$ 훔 매에서 협소나 페놀성 히드록시기의 산소가 다리결합

Table 2. Stability constants for $\mathrm{Co}(\mathrm{II}), \mathrm{Ni}(\amalg), \mathrm{Cu}(l)$, and $\mathrm{Zn}(\mathrm{ll})$ complexes of PEMP ligands in water at $25^{\circ} \mathrm{C}$ and $\mu=0.1(\mathrm{KNO})$

\begin{tabular}{|c|c|c|c|c|c|c|c|c|}
\hline \multirow{2}{*}{ Ligand } & \multicolumn{2}{|c|}{$\mathrm{Cu}(\mathrm{Il})$} & \multicolumn{2}{|c|}{$\mathrm{Ni}(\amalg)$} & \multicolumn{2}{|c|}{$\mathrm{Co}(\amalg)$} & \multicolumn{2}{|c|}{$\mathrm{Zn}$ (II) } \\
\hline & $\log \mathrm{ML}$ & $\log \mathrm{ML}_{2}$ & $\log M L$ & $\log \mathrm{ML}_{2}$ & $\log \mathrm{ML}$ & $\log \mathrm{ML}_{2}$ & $\log M L$ & $\log \mathrm{ML}_{2}$ \\
\hline Br-PEMP & 5.11 & 13.40 & 4.86 & 12.86 & 4.27 & 12.31 & 4.52 & 12.64 \\
\hline Cl-PEMP & 6.08 & 14.60 & 5.34 & 13.71 & 4.18 & 12.17 & 4.84 & 13.54 \\
\hline H-PEMP & 6.68 & 14.69 & 5.57 & 14.57 & 6.18 & 14.34 & 6.21 & 14.58 \\
\hline Naph-PEMP & 8.08 & 16.10 & 7.69 & 15.90 & 6.91 & 14.89 & 7.43 & 15.43 \\
\hline $\mathrm{CH}_{3} \mathrm{O}$-PEMP & 8.18 & 17.18 & 7.71 & 16.72 & 6.97 & 15.97 & 7.36 & 16.37 \\
\hline
\end{tabular}



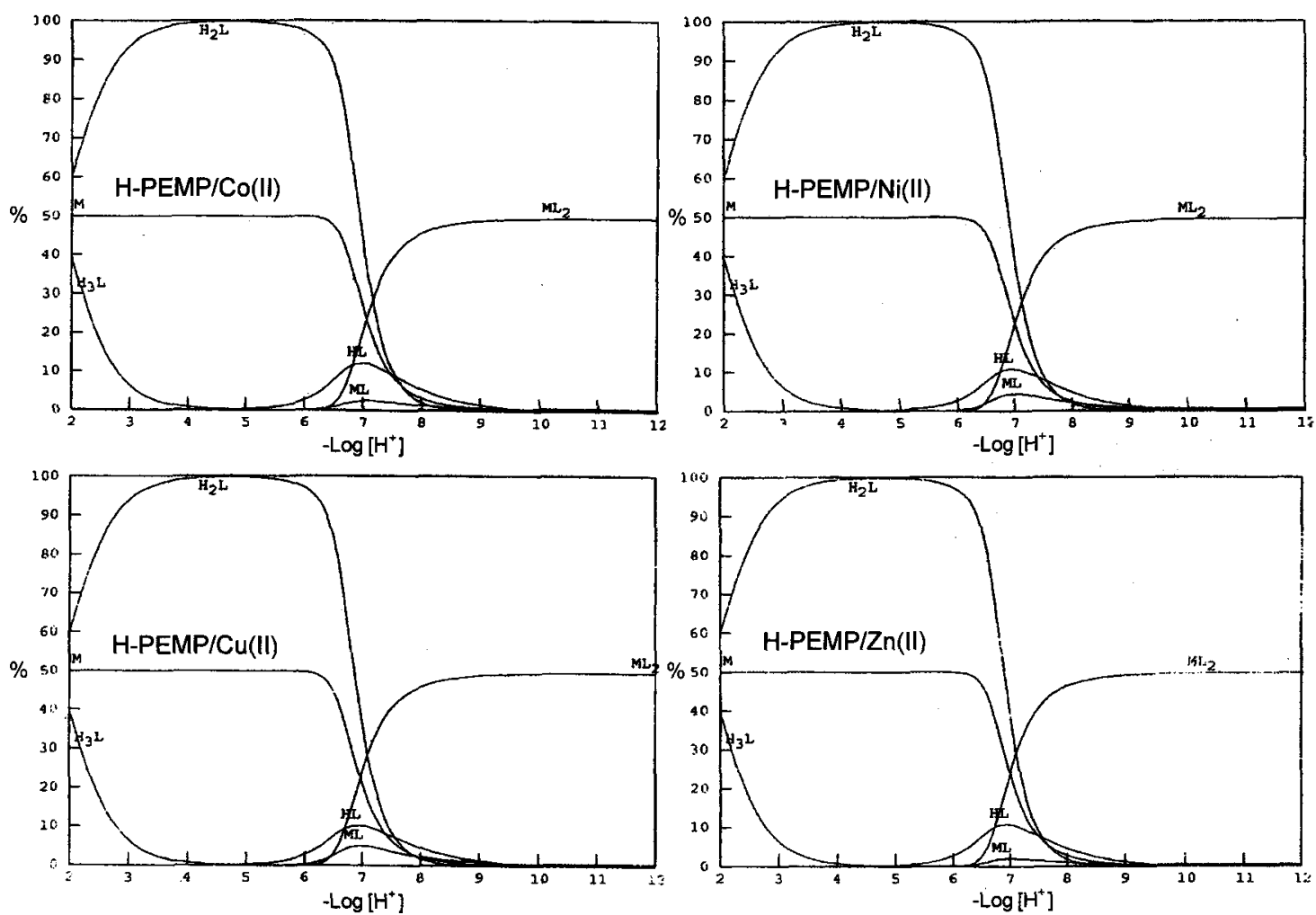

Fig. 3. Species concentrations relative to H-PEMP in aqueous solution of H-PEMP/Cu(U), H-PEMP/Ni(U), H-PEMP/Co(Il), and $\mathrm{H}-\mathrm{PEMP} / \mathrm{Zn}(\mathrm{L})$ as function of $-\log \left[\mathrm{H}^{+}\right]$.

을 하여 $(\mathrm{ML})_{2}$ 또는 $(\mathrm{MLX})_{2}(\mathrm{X}=\mathrm{Cl})$ 형태의 이합체가 생성되기도 하나, $\mathrm{Ni(II)}$ 및 $\mathrm{Zn}(\mathrm{II})$ 과 같이 $\mathrm{Cu}(\Pi)$ 이온도 주로 $1: 2$ 의 $\mathrm{ML}_{2}$ 형의 착물을 생성한다고 하였다. 5.19

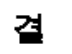

피리던과 페놀을 포함하는 $\mathrm{N}_{2} \mathrm{O}$ 계 새로운 세 자리 리 간드 H-PEMP.HCl, Br-PEMP.HCl, Cl-PEMP.HCl, $\mathrm{CH}_{3} \mathrm{O}-\mathrm{PEMP} \cdot \mathrm{HCl}$ 및 Naph-PEMP.HCl 염산 염을 합성 하였다. 합성된 리간드는 적외선 분광법, 자외선 분광 법, ${ }^{1} \mathrm{H}$ NMR 및 ${ }^{13} \mathrm{C} \mathrm{NMR}$ 분광법, 질량분석법 및 $\mathrm{C}, \mathrm{H}, \mathrm{N}$ 원소분석법을 통하여 확인하였다. 합성된 각 리간드를 전위차 법으로 적정하여 페늘성 수산기, 이차 아민기 및 피리던의 3 단졔 양성자 해러상수 $\left(\log \mathrm{K}_{\mathrm{n}}^{\mathrm{H}}\right)$ 를 구하였 다. 이때 계산된 각 리간드의 총괄 양성자 해리상수 $(\log \beta)$ 값은 $\mathrm{CH}_{3} \mathrm{O}$-PEMP $>$ Naph-PEMP > H-PEMP > $\mathrm{Cl}-\mathrm{PEMP}>\mathrm{Br}-\mathrm{PEMP}$ 로 나타났고, 전이금속 이온들의 착물 안정도상수 $\left(\log \mathrm{ML}\right.$ 및 $\left.\log \mathrm{ML}_{2}\right)$ 값은 $\mathrm{Co}(\Pi)<\mathrm{Ni}(\Pi)$
$<\mathrm{Cu}$ (II) > Zn(II)의 순서로 나타났다. 또한 치환기에 따 른 각 리간드의 전이금속 착물 안정도상수 값은 각 리 간드 훙괄 양성자 해라상수 값와 Hammett식의 치환거 상수 $\left(\delta_{p}\right)$ 값의 크기 순서인 $\mathrm{CH}_{3}$ O-PEMP > Naph-PEMP > H-PEMP > Cl-MPEP > Br-MPEP와 잘 일치하였다.

본 연구는 2002년도 대구대하ㄱㅛㅛ 교내 연구비 지원에 의하여 수행되었으며 이에 감사드립너다.

\section{인 용 문 헌}

1. Weyhermuller, T.: Paine, T. K.; Bothe, E;; Bill, E.; Chaudhuri, P. Inorg. Chim. Acta. 2002, 337, 344.

2. Xie, Y.; Bu, W.; Chan, A. S-C.; Xu, X.; Qingliang.; Zhang, Z.; Yu, J.; Fan, Y. Inorg. Chim. Acta. 2000, 310 , 257.

3. Amudha, P,; Thirumavalavan, $M_{\text {; }}$ Kandaswamy, M. Polyhedron. 1999, 18, 1371.

4. Tandon, S. S.; Chander, S.; Thompson, L. K. Inorg. Chim Acta. 2000, 300, 683. 
5. Tandon, S. S.; Chander, S.; Thompson, L. K.; Bridson, J. N.: McKee, V. Inorg. Chim. Acta. 1994, 219, 55.

6. Uma, R.: Viswanthan, R.: Palanianiandivar, M.; Lakshminarayanan, M. J. Chem. Soc. Dalton Trans. 1994, 1219.

7. Koseoglu, F; Kilic, E.; Uysal, D. Talanta. 1882.42, 1875.

8. Gerald, H.; Pasons. G. H.: Ruchester, C. H. J. Chem. Soc. Faraday. I. 1975, 71, 1058.

9. Kilic, E.: Koseoglu, F.; Basgute. O. Anal. Chim. Actt. 1994, 294, 215.

10. Hocfnagel, A. J.; Wepster, B. M. J. Chem. Soc. Perkin Trans. II. 1989, 977.

1]. Park, B. K; Lec. G. Y. J. Kor. Chem. Sor, 1986, 30, 172. 12. (a) Coleman, W. M. horg. Chim. Acta 1981, 53, 191. (b) March, J. Advanced Organic Chemistry: Reaction, Mechanisms and Structure; MaGraw Hill Book Company: New York, 1968, p 241.
13. Boggess, R. K.; Coleman, W. M.; Taylor, L. T. Inorg. Chim. Acta. 1980, 38, 183.

14. (a) Coleman. W. M.; Taylor, L. T. J. Am. Chem. Soc. 1978. 100, 1705. (b) Colenan, W. M.: Taylor, L. T. Inorg. Chem. 1977, 16, I114. (c) Coleman, W. M.; Goehring, L. T.; Taylor, L. T.: Mason, J. G.; Boggess, R. K. J. Am. Chem. Soc. 1979, 101, 2311.

15. Kim, S. D.; Jang, K. H.; Kim, J. K. J. Kor. Chem. Soc. 1998, 42, 539.

16. Kim, S. D.; Kim. J. K.; Park, Y. Y. Anat. Sci. \& Tech. 1999, 12, 347.

17. Lina, R; Viswaathan, R.; Palaniandavar, M.; Lakshminarayanan, M, J. Chem. Soc. Dalton Trans. 1994, 1219.

18. Martll, A. E.; Monkatis, R. J. Determination and Use of Stability Constant, 2 nd Ed; VCH. N.Y. 1992.

19. Taylor, L. T.; Coleman, W. M. Inorg. Chim. Acta. 1982. $63,183$. 